\title{
Research on the influence of screw spacing on magnetic shielding effectiveness of a shielding cabin
}

\author{
Longlong Chen ${ }^{1}$, Feng Ning ${ }^{2 *}$ and Chongqing Jiao ${ }^{2}$ \\ ${ }^{1}$ State Key Laboratory of Advanced Power Transmission Technology, Global Energy Interconnection Research Institute co., Ltd, \\ Beijing, 102209, China \\ ${ }^{2}$ State Key Laboratory of Alternate Electric Power System with Renewable Energy Sources, North China Electric Power University, \\ Beijing, 102206, China
}

\begin{abstract}
Large shields are usually formed by splicing small pieces of metal, resulting in gaps that affect the shielding effectiveness of the shield. Affected by the screw fixed spacing, the size of the slits will also be changed. Since it is difficult to deduce the influence of fixed spacing on shielding effectiveness by theoretical formula or software simulation, we built a $2 \mathrm{~m} * 2 \mathrm{~m} * 2 \mathrm{~m}$ shielding cabin model and explored the influence of fixed spacing on shielding effectiveness by changing the fixed spacing of screws. During measurement, the selected frequency range was $0.25-1000 \mathrm{MHz}$. In the selected frequency range, for different frequencies, different antennas were used and a total of 22 frequency points were selected for measurement. The results show that the smaller the screw spacing, the greater the shielding effectiveness. When the screw spacing is reduced by half, the shielding effectiveness increases by about $6-8 \mathrm{~dB}$, especially at low frequency. When screw spacing is $0.25 \mathrm{~m}$, the maximum shielding effectiveness is about $44 \mathrm{~dB}$, the minimum is about $25 \mathrm{~dB}$, and the average shielding effectiveness is about $35 \mathrm{~dB}$. In addition, the polarization mode and antenna position have little influence on the results. So it can be used as a guide and reference for the design of large shielding body in the future.
\end{abstract}

\section{Introduction}

With the development of intelligent communication system, wireless network equipment, electronic and electronic equipment, the influence of space electromagnetic radiation on instruments and equipment is increasing, and electromagnetic shielding has been more and more widely used in electromagnetic compatibility (EMC), anti-electromagnetic interference (EMI) design and other aspects[1-3]. Electromagnetic shielding is a practice of reducing the electromagnetic field in space by blocking the field with a metal material. At present, there have been theoretical derivation of shielding effectiveness of infinite metal plate and wire mesh screen[4-5]. In reality, there are gaps, cable holes, ventilation holes, etc. on the shield as shown in Figure 1. Electromagnetic waves can leak in (out) through these gaps or holes, destroying the integrity of the shielding, and reducing the overall shielding effectiveness. Some scholars have studied the shielding effectiveness of metal shield with holes and slits[6-7]. However, in reality, it is difficult for the slits on the shield to be equivalent to these ideal slits. For example, for the large shield, the shield is formed by splicing small pieces of metal plates, so there will inevitably be gaps in the metal plate connection. Due to the influence of fixed spacing of screws, the size of gap will change accordingly. The gap formed in this case is difficult to calculate with theoretical formulas or simulation software.

In this article, by building a $2 \mathrm{~m} * 2 \mathrm{~m} * 2 \mathrm{~m}$ metal shield, the shielding effectiveness under different fixed spacings is measured, and the influence of the screw spacing on the shielding effectiveness is analysed, so as to play a certain guiding and reference role for the design of large shielding bodies in the future. This paper is organized as follows. Section II introduces the measured method, equipment, and shield under test. In section III, the measurement results are presented. Finally, this paper is summarized in section IV.

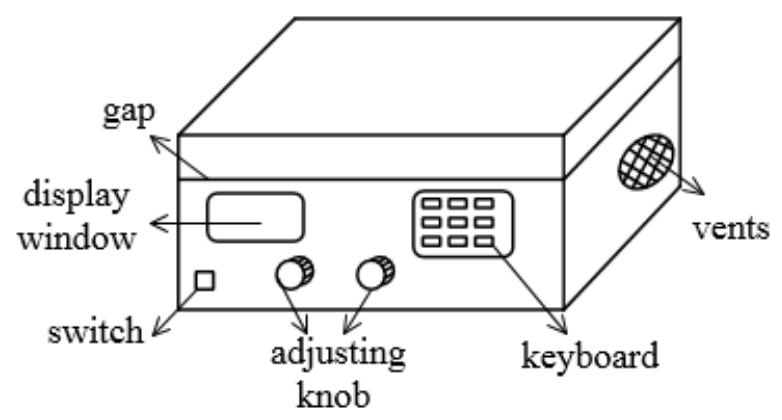

Figure.1 Holes and gaps in the shield. 


\section{Measuring standards and instruments}

\subsection{Measurement standards}

The measured method refers to the standard IEEE-Std299[8]. This standard is applicable to shielding chamber with the size of no less than $2 \mathrm{~m}$ on each side, and the applicable frequency range is $9 \mathrm{kHz}-18 \mathrm{GHz}$. The shielding effectiveness can be calculated according to Formula 1.

$$
S E=20 \log _{10}\left(\frac{V_{0}}{V_{1}}\right)
$$

Where, $V_{1}$ is the signal observed on the receiver when there is a shielding between the transmitting and receiving antennas. During measurement, the receiving antenna is placed inside the shield and the transmitting antenna is placed outside the shield. $V_{0}$ is the value observed on the receiver when the transmitting and receiving antennas are placed in an open area. In addition, when measuring $V_{0}$ and $V_{1}$ using the same antenna, the distance between transmitting and receiving antennas should keep equal.

\subsection{Measurement equipment}

The equipment used in this measurement includes: ZN1081 signal source, with frequency range is $10 \mathrm{kHz} \sim 1 \mathrm{GHz}$ and output level $-127 \sim+6 \mathrm{dBm}(50 \Omega)$; ZN3860 power amplifier, with frequency range $2 \mathrm{MHz} \sim 1 \mathrm{GHz}$ and the gain is $37 \mathrm{~dB}$, maximum output is 37dBm; The SCR3502 electromagnetic interference test receiver produced by Schaffner, Switzerland, has a frequency range of $9 \mathrm{kHz}-2.75 \mathrm{GHz}$. During the test, the output power of the signal generator is always fixed at $1 \mathrm{~mW}$.

According to the IEEE 299 standard, different transmitting and receiving antennas are used in different frequency ranges.

- In the range of $9 \mathrm{kHz}-20 \mathrm{MHz}, \mathrm{ZN} 30900 \mathrm{~A}$ loop antenna was adopted and 9 frequency points

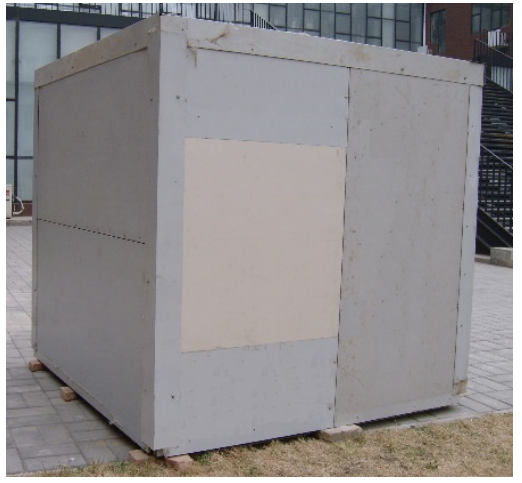

(a) were selected $(0.25 \mathrm{MHz}, 0.5 \mathrm{MHz}, 0.9 \mathrm{MHz}$, $1.5 \mathrm{MHz}, \quad 3 \mathrm{MHz}, \quad 6 \mathrm{MHz}, 9 \mathrm{MHz}, \quad 12 \mathrm{MHz}$, $15 \mathrm{MHz})$.

- In 20MHz-300MHz, ZN30505 biconical antenna was adopted and 9 frequency points were selected $(30 \mathrm{MHz}, 60 \mathrm{MHz}, 90 \mathrm{MHz}, 106 \mathrm{MHz}$, $120 \mathrm{MHz}, \quad 130 \mathrm{MHz}, \quad 180 \mathrm{MHz}, \quad 240 \mathrm{MHz}$, $300 \mathrm{MHz}$ ).

- In the range of $300 \mathrm{MHz}-1 \mathrm{GHz}, \mathrm{ZN} 30505 \mathrm{c} \log$ periodic antenna was used and 4 frequency points were selected $(400 \mathrm{MHz}, 600 \mathrm{MHz}$, $900 \mathrm{MHz}, 1000 \mathrm{MHz})$.

Furthermore, there are two modes of polarization in the measurement. Horizontal polarization means that the line where the antenna located or the plane where the loop antenna located is parallel to the ground. Vertical polarization means that the line where the line antenna located or the plane where the loop antenna located is perpendicular to the ground.

\subsection{Introduction of shield cabin}

The metal sheet shield of the valve hall is actually formed by splicing small pieces of metal plates, so there will be seams in practice to affect the shielding effect. We built a $2 \mathrm{~m} \times 2 \mathrm{~m} \times 2 \mathrm{~m}$ metal shielding enclosure in the laboratory as shown in Figure 2. The metal composite plate has three layers: the outer layer and the inner layer are aluminumzinc coated steel plates with a thickness of about $0.53 \mathrm{~mm}$. The middle layer is polyurethane foam insulation material with a thickness of about $50 \mathrm{~mm}$.

Except the measured surface, the other five surfaces were all composed of two $1 \mathrm{~m} \times 2 \mathrm{~m}$ metal plates. The measured surface was composed of one $1 \mathrm{~m} \times 2 \mathrm{~m}$, one $1 \mathrm{~m} \times 1 \mathrm{~m}$ and two $0.5 \mathrm{~m} \times 1 \mathrm{~m}$ metal plates, as shown in the Figure 2 (b). Wherein $\mathrm{L}$ is the distance between screws. In the experiment, we gradually increased the number of screws to observe the effect of screw spacing on the shielding effectiveness.

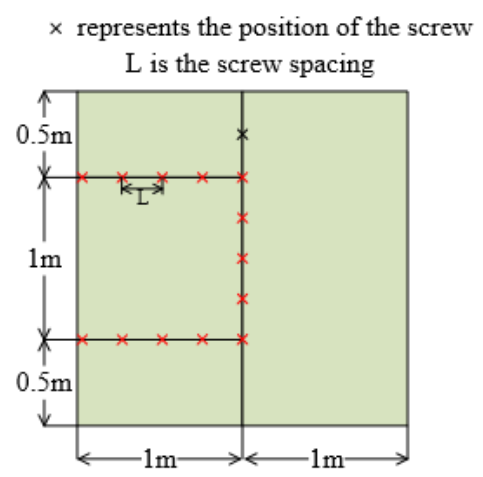

(b)

Figure.2 Schematic diagram of metal plate under test. 


\section{Measurement results}

\subsection{Measurement Results}

When the fixed spacing is $\mathrm{L}=1 \mathrm{~m}, \mathrm{~L}=0.5 \mathrm{~m}$ and $\mathrm{L}=0.25 \mathrm{~m}$ respectively, the measurement results under horizontal polarization are shown in the figure below.

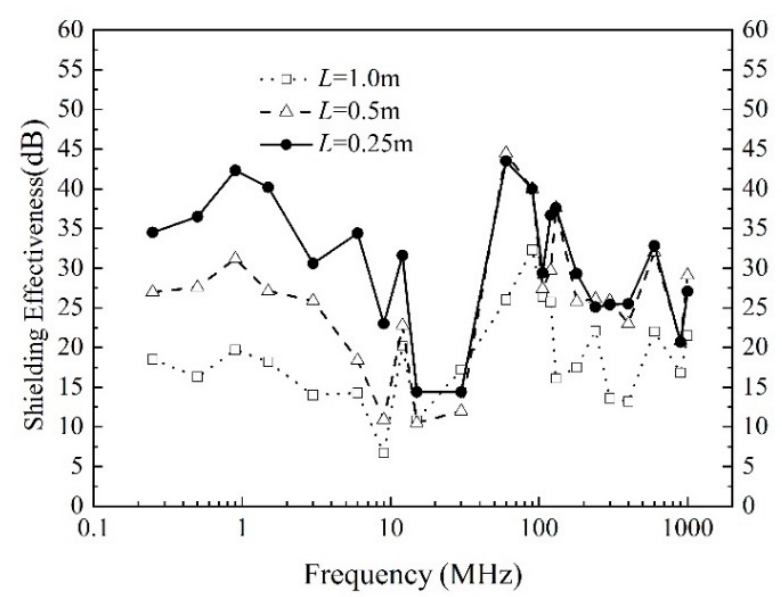

Figure.3 The measurement results under horizontal polarization.

It can be seen from the figure that the shielding effectiveness increases with the decrease of L. Especially when the frequency is low, i.e., below $30 \mathrm{MHz}$, the shielding effectiveness increases by about 6-8 $\mathrm{dB}$ when the screw spacing is reduced to half of the original. When $\mathrm{L}=0.25 \mathrm{~m}$, the maximum shielding effectiveness is about $44 \mathrm{~dB}$, the minimum is about $25 \mathrm{~dB}$, and the average shielding effectiveness is about $35 \mathrm{~dB}$. When the frequency is higher than $30 \mathrm{MHz}$, the shielding effectiveness at $\mathrm{L}=0.5 \mathrm{~m}$ is greater than that at $\mathrm{L}=1.0 \mathrm{~m}$, but the difference between the shielding effectiveness when $\mathrm{L}=0.25 \mathrm{~m}$ and that when $\mathrm{L}=0.5 \mathrm{~m}$ is small.

Different polarization modes have little influence on the results. The following table 1 and figure 4 shows the measurement results of the two polarization modes measured by the biconical antenna in the range of 20 $300 \mathrm{MHz}$ at $\mathrm{L}=1 \mathrm{~m}$.
Table 1. The measurement results of the two polarization modes measured by the biconical antenna in the range of 20 $300 \mathrm{MHz}$ at $\mathrm{L}=1 \mathrm{~m}$.

\begin{tabular}{ccc}
\hline \multirow{2}{*}{ Freqyency $(\mathrm{MHz})$} & \multicolumn{2}{c}{ Shielding Effectiveness $(\mathrm{dB})$} \\
\cline { 2 - 3 } & $\begin{array}{c}\text { Horizontal } \\
\text { polarization }\end{array}$ & $\begin{array}{c}\text { Vertical } \\
\text { polarization }\end{array}$ \\
\hline 30 & 17.2 & 20.5 \\
60 & 26 & 28.8 \\
90 & 32.3 & 30.5 \\
106 & 26.4 & 37.4 \\
120 & 25.7 & 17.4 \\
130 & 16.1 & 18.3 \\
180 & 17.5 & 11.9 \\
240 & 22.1 & 12.6 \\
300 & 13.6 & 13.7 \\
\hline
\end{tabular}

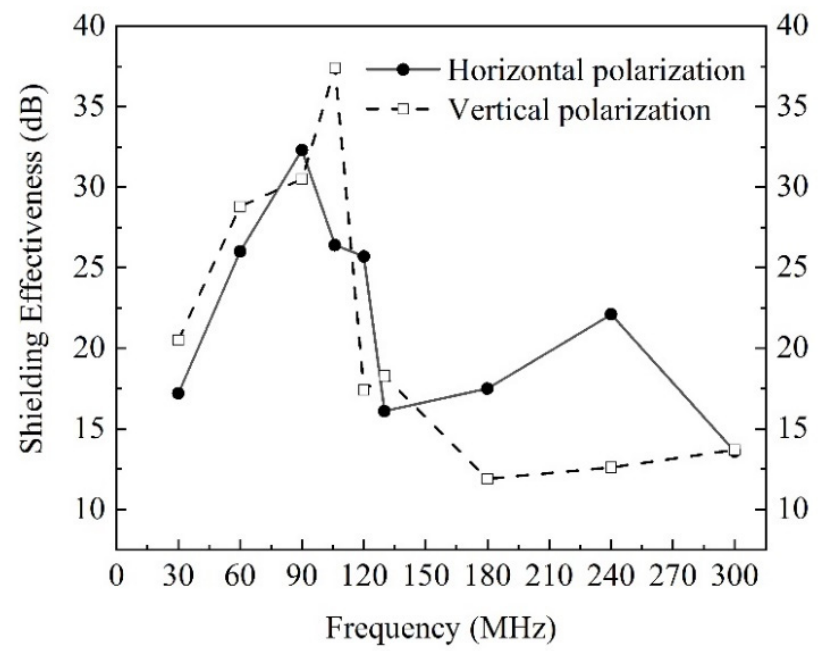

Figure.4 The measurement results of the two polarization modes measured by the biconical antenna in the range of $20-300 \mathrm{MHz}$ at $\mathrm{L}=1 \mathrm{~m}$. 
In addition, the position of the antenna is changed to observe the influence of the antenna position on the measurement results. Figure 5 shows the shielding effectiveness of the shield when the transmitting antenna is at different locations. Where, the polarization mode of the antenna is horizontal polarization and $\mathrm{L}=0.25 \mathrm{~m}$.

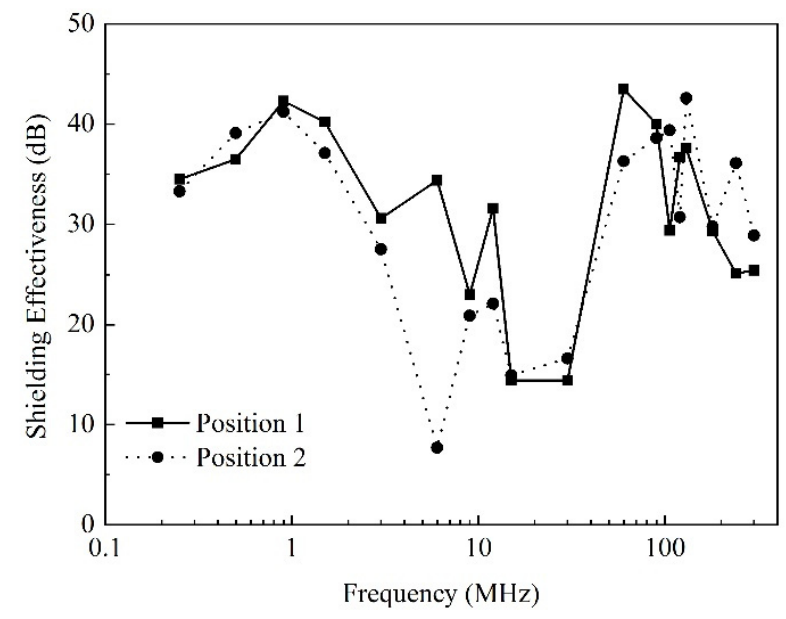

Figure.5 The measurement results of two different locations of the transmitting antenna under horizontal polarization and $\mathrm{L}=0.25 \mathrm{~m}$

\subsection{Error analysis of measurement system}

During the experiment, it is inevitable that the height of transmitting and receiving antennas is not exactly the same, as well as the angle between the antenna axes. Therefore, the influence of these influencing factors on the measurement results is tested.

When the difference of antenna height is within $10 \mathrm{~cm}$, there is basically no influence on the measurement results, and the difference is below $0.5 \mathrm{~dB}$. When the included Angle between the axes of the antenna is within 10 degrees, the influence on the measurement result is also very small, within $1 \mathrm{~dB}$.

\section{Conclusions}

Reducing the fixed spacing on the metal plate has a significant effect on improving the shielding effectiveness. The smaller the screw spacing, the greater the shielding effectiveness. The shielding effectiveness increases by about 6-8 $\mathrm{dB}$ when the screw spacing is reduced to half of the original. When $\mathrm{L}=0.25 \mathrm{~m}$, the maximum shielding effectiveness is about $44 \mathrm{~dB}$, the minimum is about $25 \mathrm{~dB}$, and the average shielding effectiveness is about $35 \mathrm{~dB}$. In addition, the difference between the measurement results under different polarizations is small. The difference between the measurement results under different antenna positions is also small.

\section{Acknowledgments}

This project was supported by State Key Laboratory of Advanced Power Transmission Technology (GEIRISKL-2018-006).

\section{References}

1. S. Kim, J. Soh, K. Shin, J. Jeong and S. Myung, "Magnetic Shielding Performance of Thin Metal Sheets Near Power Cables," in IEEE Transactions on Magnetics, vol. 46, no. 2, pp. 682-685, Feb. 2010.

2. Y. Arellano, A. Hunt and O. C. L. Haas, "Evaluation of Near-Field Electromagnetic Shielding Effectiveness at Low Frequencies," in IEEE Sensors Journal, vol. 19, no. 1, pp. 121128, 1 Jan. 1, 2019.

3. H. H. Park, J. H. Kwon, S. I. Kwak and S. Ahn, "Magnetic Shielding Analysis of a Ferrite Plate With a Periodic Metal Strip," in IEEE Transactions on Magnetics, vol. 51, no. 8, pp. 1-8, Aug. 2015, Art no. 7002408.

4. K. F. Casey, "Electromagnetic shielding behavior of wire-mesh screens," IEEE Transactions on Electromagnetic Compatibility, vol. 30, no. 3, pp. 298-306, Aug. 1988.

5. J. R. Moser, "Low-Frequency Shielding of a Circular Loop Electromagnetic Field Source," IEEE Transactions on Electromagnetic Compatibility, vol. 9, no. 1, pp. 6-18, March 1967.

6. C. Zhou, L. Gui, D. Liu, L. Lv, D. Lu and L. Lang, "Simulation and measurement for shielding effectiveness of small size metal enclosure," in IET Science, Measurement \& Technology, vol. 11, no. 1, pp. 25-29, 12017.

7. W. Bai, F. Ning, X. Yang, C. Jiao and L. Chen, "Low Frequency Magnetic Shielding Effectiveness of a Conducting Plate With Periodic Apertures," in IEEE Transactions on Electromagnetic Compatibility. DOI: 10.1109/TEMC.2020.2986249

8. IEEE Standard Method for Measuring the Effectiveness of Electromagnetic Shielding Enclosures, IEEE Standard 299-2006, 2007. 